\title{
REFLECTIONS ON ONLINE COURSE DESIGN - QUALITY MATTERSTM EVALUATION AND STUDENT FEEDBACK: AN EXPLORATORY STUDY
}

\author{
Betty Kleen, Nicholls State University, betty.kleen@nicholls.edu \\ Lori Soule, Nicholls State University, lori.soule @ nicholls.edu
}

\begin{abstract}
Based on endorsement of the Quality Matters ${ }^{\mathrm{TM}}$ program for assessing the quality of online courses by the state's Board of Regents for Higher Education, the authors' school adopted the Quality Matters ${ }^{\mathrm{TM}}$ approach to assessing online course quality. The authors completed an online Quality Matters ${ }^{\mathrm{TM}}$ workshop provided by that organization to assess their own online courses. Since students are critical stakeholders in online education, the authors also administered a survey to their students to obtain their feedback concerning whether the authors had met the standards presented in the Quality Matters ${ }^{\mathrm{TM}}$ rubric. The authors had assessed their courses did meet Quality Matters standards; student survey findings revealed students agreed that all 19 standards presented in the survey were being met in the authors' online courses.
\end{abstract}

Keywords: Online Instruction, Online Course Quality, Quality Matters ${ }^{\mathrm{TM}}$, Exploratory Study

\section{INTRODUCTION}

Pollacia, Russell, and Russell [9] write that declining numbers of CIS majors in recent years is a reason to develop innovative and high quality curricula to attract more students. Developing a strong CIS program through online learning may be a way to help turn around the declining enrollment trends. Driven both by the need for their CIS curriculum to provide more online options and the need of Universities in general to remain competitive through online offerings, many faculty in the information systems discipline now find ourselves teaching one or more online courses as part of our regular class load or as overloads.

While each school approaches bringing courses online and ensuring quality with different plans, policies and procedures, each of us individually faces the task of how to provide a quality course in a fully online environment. Depending on the approach of a particular university, prior to bringing any course online, faculty may have had structured training in not only the technology, but also in the components of providing a course structure that promotes a quality-learning environment. Some schools may have an Electronic and Distance Learning Office (or some similar name) that provides instructional design workshops specifically for online courses, or modules that can be completed independently by faculty. This training may also include technology and media training. Some institutions may require both internal review and approval of any course prior to it going live online. Yet other institutions may have more general guidelines and/or expectations for courses, thus relying on individual faculty to take responsibility for ensuring quality using their own interpretations of quality.

This paper relates recent activities at the authors' institution to institute a Quality Matters ${ }^{\mathrm{TM}}$ review of courses that are being taught online and any courses added to the online offerings in the future. The Quality Matters ${ }^{\mathrm{TM}}$ rubric and approach is reviewed, and training approaches at the authors' school discussed. Following their own completion of a Quality Matters ${ }^{\mathrm{TM}}$ workshop, the authors summarize the improvements they identified for their online courses to enhance the quality. To further validate their personal reflections on their courses, the authors surveyed students enrolled in their online courses about key Quality Matters ${ }^{\text {TM }}$ evaluation points to determine whether students perceive the quality is being provided by the faculty.

\section{MAINTAINING QUALITY COURSES USING COLLABORATIVE REVIEW METHODS}

As the number of students seeking online coursework continues to increase each year, schools will undoubtedly continue to bring more and more curricula to the online environment. Critics (sometimes faculty themselves) will continue to question how quality is maintained in the online environment. While various quality measurement standards are available, a school can benefit from selecting a particular approach so that it can be used across the institution.

\section{Support for Quality Coursework}

Puzziferro and Shelton [10] note that faculty in higher education often find themselves in an 
environment where they are being asked to reexamine the meaning of quality, especially in light of the ever increasing numbers of students who now enroll in online courses every semester. They suggest that while faculty must never compromise quality, they must work harder to ensure their standards of excellence while dealing with everlarger numbers of students who seek online learning opportunities. Chickering and Gamson's 1991 work that recognized good practice in undergraduate education has become a recognized standard for many in higher education within the past two decades; those who follow the seven principles are well on the way to providing a quality curriculum [2]. Puzziferro and Shelton [10] bring the Chickering and Gamson work to the online environment, specifically recommending how a faculty member can apply those seven principles to provide an effective online learning environment.

Beebe, Vonderwell, and Boboc [1] suggest that a pedagogical framework that "considers the learning environment differences between traditional and face-to-face classes becomes increasing imperative, both in terms of understanding the delivery and mediation of instruction." When addressing such issues as mediation, they suggest that activities such as simply counting the number of postings to an online discussion board in a course and awarding credit are insufficient mediation and evaluation. Various other aspects of online learning can also be questioned as to whether they are bringing quality to the course. If faculty operate in a vacuum in deciding how to design their online courses, quality may be lost in some areas.

In a study of online learning at Illinois community colleges, Hutti [4] found that all faculty, staff, and students demonstrated strong cohesiveness in what they perceived to be the most important quality benchmarks. He writes, "their unanimity provides credence to the idea that faculty, staff, and students all have common expectations in terms of quality and online learning even though their interaction, use, or activity within this modality is markedly different." Hutti therefore suggests that we should be able to operate with a level of confidence as to what constitutes quality online coursework.

Moore [6] notes that the Quality Matters ${ }^{\mathrm{TM}}$ rubric can provide an opportunity for educators to obtain structured feedback from their peers. She further notes that this inter-institutional collaboration suggests quality improvements in online courses across the institution.

\section{Quality Matters ${ }^{\mathrm{TM}}$ Approach to Online Course Improvement}

No single guide for ensuring quality for online courses exists. While the Quality Matters ${ }^{\mathrm{TM}}$ rubric is quite popular across the country, the Sloan-C Pillars guide developed by the Sloan Consortium and the Baldridge National Quality Program are also guides preferred by numerous institutions. Because the Board of Regents for higher education in the authors' state has subscribed to Quality Matters ${ }^{\mathrm{TM}}$, a description of that approach and its 2008-2010 rubric are detailed here.

Beginning in 2002-2003, under a FIPSE-funded project, Maryland Online, a consortium of nineteen higher education institutions, developed a peer review method and research based standards for online courses named Quality Matters ${ }^{\mathrm{TM}}$ (hereafter referred to as $\mathrm{QM})$. The rubric focuses on course design, rather than the academic content of the course [5]. The 2008-2010 rubric includes forty elements across eight standards. Although slight modifications have occurred over the years, the 2008-2010 rubric includes the following eight standards:

- Course overview and introduction

- Learning objectives

- Assessment and measurement

- Resources and materials

- Learner engagement

- Course technology

- Learner support

- Accessibility

Schools following the QM approach use the researchbased rubric and assign internal teams of three faculty members (all previously trained in QM review process) to review and assess the quality of an online course. Nankivell [7] notes that this process can serve various stakeholders, including students, faculty, course developers, and the institutions at which the online courses are offered. Pollacia [8] further supports use of the QM approach, noting that this method has "generated widespread interest and received national recognition for its peer-based approach to quality assurance and continuous improvement in online education." Although started from a FIPSE grant, QM is currently a selfsupporting organization, with hundreds of subscribers in approximately $80 \%$ of the states in the U.S. [11]. 
Nine states (including the authors' state) have adopted the QM standards statewide.

Under the QM evaluation, each of the eight standards has several key elements identified, with point values of 3,2, or 1 for each element of the standard. Using the 2008-2010 Quality Matters Rubric, these 40 elements are broken down as follows:

- $\quad 17$ are classified as essential (worth 3 points each)

- $\quad 11$ are classified as very important (worth 2 points each)

- 12 are classified as important (worth 1 point each)

When a courses is reviewed, in order to earn a certification as a QM online course, all of the essential elements must score 3 points each $(17 \times 3=$ $51)$; additionally the course design must score high enough in the other elements to earn a minimum of 72 points total ( $85 \%$ of the possible 85 points) [5].

\section{FACULTY TRAINING AT THE AUTHORS' INSTITUTION}

The authors' institution is somewhat behind many higher education institutions in percentage of course offerings available in a fully online version. However, recognizing that online course quality issues are of concern, early in the spring 2010 semester the school's e-Learning Committee unanimously recommended steps to ensure all faculty involved in teaching online courses will be properly trained in online curriculum development and that all electronic coursework will be evaluated by a committee of professionally trained peer reviewers. In its proposal to the administration, the committee set the goal of having all online courses internally evaluated by professionally trained evaluators by the end of 2010, using the Quality Matters ${ }^{\mathrm{TM}}$ rubric [13]. The committee proposed QM training because the state Board of Regents for Higher Education and the Southern Regional Education Board have both endorsed the use of QM as a tool to help address quality of online course offerings. In recent years, the state's Board of Regents has pushed for the use of QM and has paid for the schools in its system to be QM subscribers.

Recognizing the value of faculty-centered evaluation and feedback for courses, the authors of this paper signed up when the notice was distributed to participate in the first QM funded workshop offered in March. Other workshop offerings were tentatively scheduled for May, July, and October. The QM online workshop timeframe was 14 days and involved completion of 5 Modules. Each participant selected a single online course he/she taught and applied the QM rubric to that course. Although QM workshop facilitators reviewed materials posted by participants, the strongest potential for course improvement came through each participant's honest and personal reflection of whether his/her course met each of the 40 elements of the 8 standards. Workshop participants were also charged with identifying improvements that could/should be made to bring their online courses up to QM level (meaning bringing those points viewed as "essential" up to standard) or strengthening their course beyond the 85\% minimum QM specifications. Discussion board postings after completion of each workshop module allowed participants to share with and learn from other faculty who had also completed the same module. Because the workshop participants represented many different disciplines of a typical university environment as well as being from several different universities, the potential for new ideas from other perspectives was strong. Specific workshop facilitators reviewed all postings and provided feedback to individual participants.

\section{PERSONAL REFLECTIONS AND STUDENT PERCEPTIONS}

The authors of this paper both scored their own courses as meeting the $85 \%$ quality standards. While both authors assessed standards were met in all 8 areas of the rubric, they gathered additional improvement ideas from materials other workshop participants shared. When completing the course improvement plan required in module 5 of the QM workshop, author A identified improvements for the next semester the online course is taught as follows:

- Provide additional guidance for exploring the course website.

- Present each unit's objectives into the unit activity sheet instead of having students click to another link to read the objectives.

- Continue adding to the existing list of online videos and ensure that links are completely self-evident or have a purpose notation added.

- Expand the Q \& A discussion board currently in use and add Qs from current semester students with appropriate teacherprovided answers.

- Add an ADA compliance statement from the Course Management system. Post the hard 
copy transcripts from teacher-prepared MP3 lectures.

After completing Module 5, author B identified additional improvements that can be made:

- Provide additional guidance for exploring the course website and getting started.

- Clarify how the points and percentages are related for the student's final grade assessment.

- Rewrite some of the explanations of what the students need to do and why they are doing it.

The authors shared the opinion that the QM course facilitators did not provide a significant amount of feedback. While they surmised that other participants who discovered their courses might not be meeting all standards might have received more feedback, the question remained as to whether other stakeholders would perceive that the QM standards were being met. Although an internal team at the researchers' university will use the QM approach to evaluate the authors' courses at a later date to provide feedback, nothing formal was planned during the remainder of the term.

Ralston-Berg and Nath [12] studied the student perspective of what makes a quality online course as part of the University of Wisconsin's efforts to ensure faculty development efforts are in line with the online students' needs. Students completed a survey instrument that included features representing the eight quality standards from the QM 2005-2006 rubric using a 6-point response scale as to how valuable the features were. In the Ralston-Berg and Nath study, students ranked the items QM rates as "essential" lower on the 1-6 scale. However, Ralston-Berg and Nath concluded from findings that all items on the QM rubric were identified as valuable to students. For most of the items on the survey, students indicated QM standards rated 2 on the QM scale are just as important as the QM standards rated 3 on the QM scale. Fisher and Wright [3] also used students' feedback in a study to help identify problem areas, especially for testing. Based on ideas from these two sources, the researchers in the current study elected to survey their own students to obtain feedback.

\section{DATA AND METHODOLOGY}

Data for the current study were gathered with convenience sampling. A short instrument consisting of five demographic questions, nineteen statements based upon a 4-point Likert scale (strongly disagree, disagree, agree, strongly agree), and two open-ended questions was administered to two online classes. The 4-point response scale was used specifically to prevent students from simply taking the "no opinion" or middle ground perspective in answering the questions. One class contained 28 students enrolled in a freshman level computer literacy course, and the other class contained 22 students enrolled in a sophomore CIS course required of all business majors. One hundred percent participation of students still participating in the classes in late April was achieved between the two classes resulting in $\mathrm{N}=50$. Each student received a unique code which identified the student for the purpose of awarding participation points. These participation points represented less than 0.005 percentage points that the students were eligible to earn during the semester.

\section{Independent Variables}

Thirty-two percent of the 50 respondents were male while $68 \%$ were female. Sixty-four percent were within the ages of 18-24 while the remaining $36 \%$ were ages 25 and older. Fourteen percent were classified as freshmen, $22 \%$ were sophomores, $30 \%$ were juniors, and $34 \%$ were seniors (some nonbusiness students leave their computer literacy class until senior year). Forty-eight percent reported they never had taken an online class before while $52 \%$ stated that they had taken an online class before. Two percent were enrolled in 1-3 hours for the semester, $6 \%$ were enrolled in 4-6 hours, $32 \%$ were enrolled in 10-12 hours, $30 \%$ were enrolled in 13-15 hours, and $30 \%$ were enrolled in 16 or more hours.

\section{Correlations in the Independent Variables}

The researchers used correlation tools to look for relationships between the pairs of independent variables and between the independent and dependent variables. Gender, age, and classification are positively correlated with first online class (.316, .364, and .330). The researchers speculate the positive correlation of gender and first online class is due to the convenience and accessibility of taking an online class. Females are more likely to have taken an online class previously; they can stay at home with families, or perhaps balance work, family, and school continuation. The researchers also speculate that the positive correlations between age and first online 
class and classification and first online class are due to older students being less needing of "hand holding." The older students have life experiences that they can draw upon for the online class, and for the juniors and seniors, they are more likely to have previously taken an online class.

Age is positively correlated to the dependent variables "A statement introduces the student to the purpose of the course and to its components" (.290), "The course learning objectives describe outcomes that are measurable" (. 282), and "All learning objectives are stated clearly and written from the students' perspective" (.338). The researchers speculate that older students may pay more attention to the syllabus, take the time to look at objectives for each unit/section, and look at more posted materials than younger students. Older students may perceive doing this can help them stay focused to be able to earn higher grades in the course. More life skills in general may mean they take a "read the fine print" attitude to reviewing what the instructor has posted.

Classification is negatively correlated to the dependent variable "The types of assessments selected measure the stated learning objectives and are consistent with course activities and resources" (.294); the researchers could not speculate any reasons why this negative correlation exists.

First online class is positively correlated to the dependent variables "Learning activities foster instructor-student, content-student, and if appropriate to the course, student-student interaction" (.358) and "The tools and media support student engagement and guide the student to become an active learner" (.295). The researchers speculate that the students having previously taken an online class better understood the different interactions that could occur in the course, would be more likely to participate in the different interactions, and would probably engage with the tools and media available to them in the course to become an active learner.

\section{STATISTICAL ANALYSIS}

The mean and standard deviation for each of the statements were computed (see Table 1). The dependent variable "Instructions make clear how to get started and where to find various course components" had the highest mean $(M=3.64, S D=$ .525), while the dependent variable "Learning activities foster instructor-student, content-student, and if appropriate to the course, student-student interaction" had the lowest $(M=3.20, S D=.700)$. Relating to the 19 QM rubric questions on the survey, Volume XI, No. 2, 2010 the researchers formulated hypotheses (H1-H19) about the differences in the mean of the dependent variables by gender. However, using independent samples t-test, none of the hypotheses were found to be statistically significant.

The researchers also formulated hypotheses, again tested using independent samples t-test, about the differences in the mean of the different dependent variables by age. Three hypotheses in this grouping were found to be statistically significant. (Only the three hypotheses found to be statistically significant are presented in abbreviated Table 2 below because of space limitations.) The first hypothesis was do persons 18-24 years of age feel the same about the statement "A statement introduces the student to the purpose of the course and to its components" as persons 25 years of age or older $(\mathrm{H}-21)$ ? Persons 18 24 years of age had a mean of 3.31 while the persons 25 years of age or older had a mean of 3.61. Equal variances were assumed (sig. $=.328$ ) and the hypothesis (H-21) of equal means was rejected (sig. = .041).

The second hypothesis was do persons 18-24 years of age feel the same about the statement "The course learning objectives describe outcomes that are measurable" as persons 25 years of age or older $(\mathrm{H}-$ 23)? Persons 18-24 years of age had a mean of 3.25 while the persons 25 years of age or older had a mean of 3.56. Equal variances were assumed $(\mathrm{sig} .=.276)$ and the hypothesis (H-23) of equal means was rejected $($ sig. $=.047)$.

The third hypothesis was do persons 18-24 years of age feel the same about the statement "All learning objectives are stated clearly and written from the students' perspective" as persons 25 years of age or older (H-25)? Persons 18-24 years of age had a mean of 3.34 while the persons 25 years of age or older had a mean of 3.72. Equal variances were assumed (sig. $=.154)$ and the hypothesis $(\mathrm{H}-25)$ of equal means was rejected (sig. $=.017)$.

Continuing with the same testing method of independent samples t-test, the researchers also formulated hypotheses about the differences in the mean of the different dependent variables by online class experience. Table 3 presents the two hypotheses that were statistically significant. The first hypothesis was do persons with online class experience feel the same about the statement "Learning activities foster instructor-student, contentstudent, and if appropriate to the course, studentstudent interaction" as persons without any previous online class experience (H-52)? Persons with no
Issues in Information Systems 
previous online class experience had a mean of 2.96 while the persons having previous online class experience had a mean of 3.46. Equal variances were assumed (sig. $=.208)$ and the hypothesis $(\mathrm{H}-52)$ of equal means was rejected $(\mathrm{sig} .=.011)$. 
Table 1. Mean and Standard Deviation of Dependent Variables

\begin{tabular}{|c|c|c|}
\hline Statements & Mean & STDV \\
\hline Instructions make clear how to get started and where to find various course components. & 3.64 & .525 \\
\hline Course grading policy is stated clearly. & 3.58 & .642 \\
\hline Specific and descriptive criteria are provided for the evaluation of students' work and participation. & 3.56 & .501 \\
\hline Learning activities promote the achievement of the stated learning objectives. & 3.54 & .542 \\
\hline Instructional materials contribute to the achievement of the stated course and module/unit learning objectives. & 3.52 & .505 \\
\hline $\begin{array}{l}\text { Types of assessments selected measure the stated learning objectives and are consistent with course activities } \\
\text { and resources. }\end{array}$ & 3.52 & .580 \\
\hline $\begin{array}{l}\text { Module/unit learning objectives describe outcomes that are measurable and consistent with the course-level } \\
\text { objectives. }\end{array}$ & 3.50 & .505 \\
\hline $\begin{array}{l}\text { The course incorporates American Disabilities Act standards and reflects conformance with institutional } \\
\text { policy regarding accessibility in online and hybrid courses. }\end{array}$ & 3.50 & .505 \\
\hline $\begin{array}{l}\text { Tools and media support the learning objectives, and are appropriately chosen to deliver the content of the } \\
\text { course. }\end{array}$ & 3.50 & 614 \\
\hline All learning objectives are stated clearly and written from the students' perspective. & 3.48 & .544 \\
\hline Instructions to students on how to meet the learning objectives are adequate and stated clearly. & 3.48 & .544 \\
\hline Navigation throughout the online components of the course is logical, consistent, and efficient. & 3.48 & .544 \\
\hline $\begin{array}{l}\text { Clear standards are set for instructor responsiveness and availability (turn-around time for email, grade } \\
\text { posting, etc.) }\end{array}$ & 3.44 & .577 \\
\hline A statement introduces the student to the purpose of the course and to its components. & 3.42 & .499 \\
\hline Relationship between the instructional materials and the learning activities is clearly explained to the student. & 3.42 & .538 \\
\hline Course learning objectives describe outcomes that are measurable. & 3.36 & .525 \\
\hline Tools and media support student engagement and guide the student to become an active learner. & 3.36 & .598 \\
\hline Minimum technical skills expected of the student are clearly stated. & 3.28 & .701 \\
\hline $\begin{array}{l}\text { Learning activities foster instructor-student, content-student, and if appropriate to the course, student-student } \\
\text { interaction. }\end{array}$ & 3.20 & .700 \\
\hline
\end{tabular}

Table 2. Independent Samples t-test Grouped by Age, N=50

\begin{tabular}{|c|c|c|c|}
\hline Hypothesis & $\begin{array}{c}\text { Met Test } \\
\text { Assumption }\end{array}$ & $\begin{array}{c}\text { Test } \\
\text { Outcome }\end{array}$ & $\begin{array}{l}\text { Sig. } \\
\text { Level }\end{array}$ \\
\hline $\begin{array}{l}\mathrm{H}_{\mathrm{o}} \text { : Mean of "A statement introduces the student to the purpose of the course and to its } \\
\text { components" for persons } 18-24 \text { years of age = Mean of "A statement introduces the } \\
\text { student to the purpose of the course and to its components" for persons } 25 \text { years of } \\
\text { age or older } \\
\mathrm{H}_{\mathrm{a}} \text { : Mean of "A statement introduces the student to the purpose of the course and to its } \\
\text { components" for persons } 18-24 \text { years of age } \neq \text { Mean of "A statement introduces the } \\
\text { student to the purpose of the course and to its components" for persons } 25 \text { years of } \\
\text { age or older }\end{array}$ & $\begin{array}{c}\text { Yes, equal } \\
\text { variances } \\
\text { assumed }\end{array}$ & Reject $\mathrm{H}_{\mathrm{o}}$ & .041 \\
\hline $\begin{array}{l}\mathrm{H}_{\mathrm{o}} \text { : Mean of "The course learning objectives describe outcomes that are measurable" } \\
\text { for persons } 18-24 \text { years of age = Mean of "The course learning objectives describe } \\
\text { outcomes that are measurable" for persons } 25 \text { years of age or older } \\
\mathrm{H}_{\mathrm{a}} \text { : Mean of "The course learning objectives describe outcomes that are measurable" } \\
\text { for persons } 18-24 \text { years of age } \neq \text { Mean of "The course learning objectives describe } \\
\text { outcomes that are measurable" for persons } 25 \text { years of age or older }\end{array}$ & $\begin{array}{c}\text { Yes, equal } \\
\text { variances } \\
\text { assumed }\end{array}$ & Reject $\mathrm{H}_{\mathrm{o}}$ & .047 \\
\hline $\begin{array}{l}\mathrm{H}_{\mathrm{o}} \text { : Mean of "All learning objectives are stated clearly and written from the students' } \\
\text { perspective" for persons } 18-24 \text { years of age = Mean of "All learning objectives are } \\
\text { stated clearly and written from the students' perspective" for persons } 25 \text { years of } \\
\text { age or older } \\
\mathrm{H}_{\mathrm{a}} \text { : Mean of "All learning objectives are stated clearly and written from the students' } \\
\text { perspective" for persons } 18-24 \text { years of age } \neq \text { Mean of "All learning objectives are } \\
\text { stated clearly and written from the students' perspective" for persons } 25 \text { years of } \\
\text { age or older }\end{array}$ & $\begin{array}{c}\text { Yes, equal } \\
\text { variances } \\
\text { assumed }\end{array}$ & Reject $\mathrm{H}_{\mathrm{o}}$ & .017 \\
\hline
\end{tabular}


Table 3. Independent Samples t-test Grouped by Online Course Experience, N=50

\begin{tabular}{|c|c|c|c|}
\hline Hypothesis & $\begin{array}{c}\text { Met Test } \\
\text { Assumption }\end{array}$ & $\begin{array}{c}\text { Test } \\
\text { Outcome }\end{array}$ & $\begin{array}{c}\text { Sig. } \\
\text { Level }\end{array}$ \\
\hline $\begin{array}{l}\mathrm{H}_{\mathrm{o}} \text { : Mean of "Learning activities foster instructor-student, content-student, and if } \\
\text { appropriate to the course, student-student interaction" for persons with online } \\
\text { course experience= Mean of "Learning activities foster instructor-student, } \\
\text { content-student, and if appropriate to the course, student-student interaction" } \\
\text { for persons with no online course experience } \\
\mathrm{H}_{\mathrm{a}} \text { : Mean of "Learning activities foster instructor-student, content-student, and if } \\
\text { appropriate to the course, student-student interaction" for persons with online } \\
\text { course experience } \neq \text { Mean of "Learning activities foster instructor-student, } \\
\text { content-student, and if appropriate to the course, student-student interaction" } \\
\text { for persons with no online course experience }\end{array}$ & $\begin{array}{c}\text { Yes, equal } \\
\text { variances } \\
\text { assumed }\end{array}$ & Reject $\mathrm{H}_{\mathrm{o}}$ & .011 \\
\hline $\begin{array}{l}\mathrm{H}_{\mathrm{o}} \text { : Mean of "The tools and media support student engagement and guide the } \\
\text { student to become an active learner" for persons with online course } \\
\text { experience= Mean of "The tools and media support student engagement and } \\
\text { guide the student to become an active learner" for persons with no online } \\
\text { course experience } \\
\mathrm{H}_{\mathrm{a}} \text { : Mean of "The tools and media support student engagement and guide the } \\
\text { student to become an active learner" for persons with online course } \\
\text { experience } \neq \text { Mean of "The tools and media support student engagement and } \\
\text { guide the student to become an active learner" for persons with no online } \\
\text { course experience }\end{array}$ & $\begin{array}{c}\text { Yes, equal } \\
\text { variances } \\
\text { assumed }\end{array}$ & Reject $\mathrm{H}_{\mathrm{o}}$ & .038 \\
\hline
\end{tabular}

The other hypothesis was do persons with online class experience feel the same about the statement "The tools and media support student engagement and guide the student to become an active learner" as persons without any online class experience (H-55)? Persons with online class experience had a mean of 3.19 while the persons having no online class experience had a mean of 3.54. Equal variances were assumed (sig. $=.995)$ and the hypothesis $(\mathrm{H}-55)$ of equal means was rejected $(\mathrm{sig} .=.038)$. Students were also invited to write open ended comments about what could be added to the course design to improve the course. A number of students wrote support statements for the clarity the instructors provided concerning expectations, objectives, and activities to be completed. The written comments did, as expected, contain an occasional complaint such as needing a longer time to complete timed quizzes. Other suggestions included the following that could improve the courses:

- use of a "due date" tab

- $\quad$ addition of an instant messaging system with the instructor available at a designated time to address questions (neither instructor had a specific chat time online, but did maintain set virtual office hours)

- reorganization of contents in some of the folders in the course management system
- increased instructor help with a particular unit

- longer MP3 lectures from the instructor

A review of the survey findings and the written comments provided by students has helped confirm to the authors that they are addressing the various standards of the QM rubric successfully from the student stakeholder perspective.

\section{CONCLUSIONS}

People who work in higher education recognize that the demand for online courses keeps growing each year. Especially in disciplines with enrollments that have declined in recent years, providing an electronic delivery system may be a way to help turn around those downward trends. While each school may have its own plans, policies and procedures to follow when adding online courses, those policies and procedures should present an organized way to address quality in the course design.

While numerous quality measurement instruments and programs exist, this paper has focused on the Quality Matters ${ }^{\mathrm{TM}}$ program because of the preferences of the authors' state Board of Regents for Higher Education and their own institution. Literature reflects that the QM program has national participation and has received extensive recognition 
for its peer-based approach. The authors' personal participation in an official QM workshop revealed that individual reflection and evaluation against the QM rubric were key necessities in gaining benefits from the workshop.

The authors' personal assessments rated their own online courses as meeting QM standards; additionally, to seek other stakeholder opinions, the authors gathered student feedback through a survey. The percentage of students who were in their first online course compared to those who had previous online coursework was nearly equal. Previous online coursework was positively correlated to student responses to tools supporting student engagement and to presence of learning activities that fostered instructor-student, and content-student interaction. Age was positively correlated with QM questions concerning statements introducing students to the course purpose, learning outcomes expressed in a measurable format, and learning objectives presented from the student point of view.

Based on a 4-point Likert scale, the highest rated QM statement was "Instructions make clear how to get started and where to find various course components," while the lowest rated statement was, "Learning activities foster instructor-student, contentstudent, and if appropriate to the course, studentstudent interaction." Although the lowest score still remained on the "agree" side of the scale, this suggests that room for enhancing these types of activities still exists in the eyes of the survey respondents, especially those students who are taking an online course for the first time.

Survey analysis revealed that older students responded significantly more positively to the statement, "A statement introduces the student to the purpose of the course and to its components." Older students also responded significantly more positively to the statement, "The course learning objectives describe outcomes that are measurable." Students with previous online course experience responded significantly more positively to the statement, "Learning activities foster instructor-student, contentstudent, and if appropriate to the course, studentstudent interaction."

Overall, survey findings revealed that students agreed the authors were providing the QM expectations of a quality online course.

\section{RECOMMENDATIONS}

As the title of this study reflects, this is an exploratory study. An expanded study could provide much more generalized results. Since the authors' school intends to proceed in having all faculty teaching online courses complete official QM workshops in upcoming months, surveying online students of other faculty can provide more feedback concerning course quality. Although the QM standards group the statement, "Learning activities foster instructor-student, content-student, and if appropriate to the course, student-student interaction" into a single element, this could be divided into three separate survey questions to better determine whether students see difference levels among the three types of interaction provided.

Surveys and/or interviews with faculty once they have completed the QM workshop can provide additional insight as to what aspects of the QM rubric may be most challenging to attain. This could provide additional ideas for faculty workshops or one-on-one assistance in improving quality of online courses.

Finally, faculty who teach online at other institutions may want to replicate or modify the survey used in this study to obtain student stakeholder feedback concerning their own online courses.

\section{REFERENCES}

1. Beebe, R., Vonderwell, S., and Boboc, M. (2010). Emerging patterns in transferring assessment practices from $\mathrm{F} 2 \mathrm{f}$ to online environments. Electronic Journal of e-Learning, 8(1), 1-12. Available online at www.ejel.org.

2. Chickering, A.W., and Gamson, Z.F. (1991). Applying the seven principles for good practice in undergraduate education: Vol. 47. New directions for teaching and learning. San Francisco: Jossey-Bass Inc.

3. Fisher, E., and Wright, V. (2010). Online course design through usability testing. MERLOT Journal of Online Learning and Teaching, 6(1).

4. Hutti, D. (2007). Online learning, quality, and Illinois community colleges. MERLOT Journal of Online Learning and Teaching, (3)1.

5. MarylandOnline.Inc. (2009). Quality Matters Rubric Standards 2008-2010 Edition with Assigned Point Values. Retrieved on March 25, 2010, from http://qminstitute.org/home/ 
Public\%20Library/

About\%20QM/

Rubric Standards2008-2010.pdf.

6. Moore, J. (n.d.). Collaboration online: Sloan-C Resources. Retrieved on March 25, 2010 from http://scholar.google.com/.

7. Nankivell, K., Whittington, J., and Colwell, J. (2007). Issues in online courses for computer graphics. American Society for Engineering Education. Retrieved on March 25, 2010, from http://scholar.google.com/.

8. Pollacia, L., and McCallister, T. (2009). Using Web 2.0 technologies to meet Quality Matters TM requirements, Journal of Information Systems Education, 20(2), 155 - 164.

9. Pollacia, L., Russell, J., and Russell, B. (2009). Developing an online program in computer information systems using Quality Matters TM Standards. MERLOT Journal of Online Learning and Teaching, 5(2).

10. Puzziferro, M., and Shelton, K. (2009). Supporting online faculty - revisiting the seven principles (A few years later). Online Journal of Distance Learning Administration, 12(3). Retrieved on March 25, 2010, from http.scholar.google.com.

11. Quality Matters (2010). Quality Matters Current Subscriptions by State. Retrieved on April 12, 2010, from https://qualitymatters.dabbledb.com/ page/qualitymattersenterpriseinformationsystem/

EFmDKjqC\#.

12. Ralston-Berg, P., and Nath, L. (2008). What makes a quality online course? The student perspective. Proceedings of the $24^{\text {th }}$ Annual Conference on Distance Teaching and Learning. Retrieved from http://scholar.google.com.

13. Simoncelli, A. (2010). Quality Matters Training Proposal. (Internal Communication). Nicholls State University. 